\title{
BMJ Open Determinants of COVID-19 preventive behaviours among adults with chronic diseases in the USA: an analysis of the nationally representative COVID-19 impact survey
}

Jessica Y. Islam (D) , ${ }^{1}$ Denise C. Vidot, ${ }^{2}$ Marlene Camacho-Rivera ${ }^{3}$

To cite: Islam JY, Vidot DC, Camacho-Rivera M. Determinants of COVID-19 preventive behaviours among adults with chronic diseases in the USA: an analysis of the nationally representative COVID-19 impact survey. BMJ Open 2021;11:e044600. doi:10.1136/ bmjopen-2020-044600

- Prepublication history for this paper is available online. To view these files, please visit the journal online (http://dx.doi. org/10.1136/bmjopen-2020044600).

Received 07 September 2020 Revised 13 December 2020 Accepted 21 December 2020

Check for updates

(C) Author(s) (or their employer(s)) 2021. Re-use permitted under CC BY-NC. No commercial re-use. See rights and permissions. Published by BMJ.

${ }^{1}$ Lineberger Comprehensive Cancer Center, University of North Carolina at Chapel HIII, Chapel Hill, North Carolina, USA

${ }^{2}$ School of Nursing and Health Studies, University of Miami, Coral Gables, Florida, USA ${ }^{3}$ Department of Community Health Sciences, SUNY

Downstate Health Sciences University, Brooklyn, New York, USA

Correspondence to Dr Jessica Y. Islam; islamjy@email.unc.edu

\section{ABSTRACT}

Background Preventive behaviours have been recommended to control the spread of SARS-CoV-2. Adults with chronic diseases (CDs) are at higher risk of COVID19-related mortality compared to the general population. Our objective was to evaluate adherence to COVID-19 preventive behaviours among adults without CDs compared with those with CDs and identify determinants of non-adherence to COVID-19 preventive behaviours.

Study design Cross-sectional.

Setting and participants We used data from the nationally representative COVID-19 Impact Survey $(n=10760)$ conducted in the USA.

Primary measures Adults with CDs were categorised based on a self-reported diagnosis of diabetes, high blood pressure, heart disease/heart attack/stroke, asthma, chronic obstructive pulmonary disease (COPD), bronchitis or emphysema, cystic fibrosis, liver disease, compromised immune system, or cancer (54\%).

Results Compared with adults without CDs, adults with CDs were more likely to adhere to preventive behaviours including wearing a face mask $\left(\chi^{2}-p<0.001\right)$, social distancing $\left(\chi^{2}-p<0.001\right)$, washing or sanitising hands $\left(\chi^{2}-p<0.001\right)$, and avoiding some or all restaurants $\left(\chi^{2}\right.$ $\mathrm{p}=0.002)$ and public or crowded places $\left(\chi^{2}-p=0.001\right)$. Adults with a high school degree or below [Adjusted prevalence ratio (aPR):1.82, 95\% Confidence interval (CI) 1.04 to 3.17], household income <US\$50000 (aPR:2.03, 95\% Cl 1.34 to 2.72), uninsured (aPR:1.65, $95 \% \mathrm{Cl} 1.09$ to 2.52), employed (aPR:1.48, 95\% $\mathrm{Cl} 1.02$ to 2.17 ), residing in rural areas (aPR: $1.70,95 \% \mathrm{Cl} 1.01$ to 2.85 ) and without any $\mathrm{CD}$ (aPR:1.78, 95\% $\mathrm{Cl} 1.24$ to 2.55$)$ were more likely to not adhere to COVID-19 preventive behaviours.

Conclusion Adults with CDs are more likely to adhere to recommended COVID-19 preventive behaviours. Public health messaging targeting specific demographic groups and geographic areas, such as adults without CD or adults living in rural areas, should be prioritised.

\section{BACKGROUND}

In the USA, the COVID-19 pandemic has led to the death of over 230000 individuals as of 18 November 2020. ${ }^{1}$ Epidemiologic data suggest
Strengths and limitations of this study

- We were able to use nationally representative survey data collected from adults residing in the USA, which improves the generalisability of the findings.

- We were able to compare preventive behaviours of adults with and without chronic diseases based on self-report and include several conditions including diabetes, high blood pressure, heart disease/heart attack/stroke, asthma, COPD, bronchitis or emphysema, cystic fibrosis, liver disease, compromised immune system or cancer.

- Data for this analysis, including reported preventive behaviours, were based on self-report, which may be subjected to social desirability bias.

- We were unable to address important factors in evaluating adherence of preventive behaviours, such as frequency of practising preventive behaviours in the past 7 days.

- We were unable to probe further into why adults may not be adhering to recommended COVID-19 prevention behaviours as those data were not available.

that certain groups are at higher risk of developing and dying from COVID-19 including older adults, adults with chronic diseases and the immunocompromised. ${ }^{2}$ Currently, in the absence of an effective prophylactic vaccine against SARS-CoV-2, the virus that leads to COVID-19, prominent public health authorities, including the Centres for Disease Control and Prevention (CDC), have recommended certain preventive behaviours. ${ }^{3}$ The most commonly recommended preventive behaviours include the ' $3 \mathrm{Ws}$ ', which include wear a mask, wash your hands and watch your distance (ie, social distancing). ${ }^{4}$ Other preventive behaviours include avoiding highrisk people, avoiding crowds and large gatherings, and generally staying home when able. These preventive behaviours have proven successful in several countries, including New 
Zealand, Vietnam and Taiwan, by stopping the spread of COVID-19 through successful enforcement of populationlevel prevention guidelines. ${ }^{56}$ However, in the USA, many are not practising recommended preventive behaviours, and practice varies greatly by demographic groups and chronic disease groups. ${ }^{7}$ At the onset of the pandemic, differences in adherence to preventive behaviour were identified among adults with and without various chronic diseases, for example, adults with immune conditions were two times more likely to report wearing a face mask when compared with individuals without immune conditions. $^{7}$ Additionally, in the general population, recent reports show that adherence to preventive behaviours, particularly wearing masks, varies greatly across the USA based on location suggesting that mask use is high in the Northeast and the West,and lower in the plains and parts of the South. ${ }^{8}$ With the recent rise of cases of COVID$19^{910}$ and reports suggesting variability in adherence to preventive behaviours in various geographic areas within the USA, it is important to examine the changes in COVID-19 preventive behaviours throughout the pandemic period. Our objective was to evaluate adherence to preventive behaviours among adults in the USA, specifically to compare adults with and without a history of physical chronic conditions. Additionally, to identify target demographic groups for tailored public health messaging, we assessed determinants of non-adherence to select COVID-19 preventive behaviours.

\section{METHODS}

\section{COVID-19 Impact Survey}

Data for these analyses were obtained from the publicly available COVID-19 Household Impact Survey, conducted by the nonpartisan and objective research organisation (NORC) at the University of Chicago for the Data Foundation. The COVID-19 Household Impact Survey is a philanthropic effort to provide national and regional statistics about physical health, mental health, economic security and social dynamics in the USA. ${ }^{11}$ The survey is designed to provide weekly estimates of the United States (US) adult (ages 18 and older) population nationwide and for 18 regional areas including 10 states $(\mathrm{CA}, \mathrm{CO}$, FL, LA, MN, MO, MT, NY, OR and TX) and 8 metropolitan statistical areas (Atlanta, Baltimore, Birmingham, Chicago, Cleveland, Columbus, Phoenix and Pittsburgh). Currently, data from week 1 (20-26 April 2020), week 2 (4-10 May 2020) and week 3 (30 May to 8 June 2020) are available, which were merged for this analysis. Details regarding the data set and data collection methods have been previously published. ${ }^{1213}$

\section{AmeriSpeak sample}

Funded and operated by NORC at the University of Chicago, AmeriSpeak is a probability-based panel designed to be representative of the US household population. During the initial recruitment phase of the AmeriSpeak panel, randomly selected US households were sampled using area probability and address-based sampling, with a known, non-zero probability of selection from the NORC National Sample Frame. These sampled households were then contacted by US mail, telephone and field interviewers (face to face). The panel provides sample coverage of approximately $97 \%$ of the US household population. Those excluded from the sample include people with PO Box only addresses, some addresses not listed in the US Postal Service Delivery Sequence File and some newly constructed dwellings. While most AmeriSpeak households participate in surveys by web, noninternet households were able to participate in AmeriSpeak surveys by telephone. Households without conventional internet access but having web access via smartphones could participate in AmeriSpeak surveys by web. AmeriSpeak panellists participate in NORC studies or studies conducted by NORC on behalf of governmental agencies, academic researchers and media and commercial organisations. Interviews were conducted in English and Spanish. Panellists were offered a US $\$ 5$ monetary incentive for completing the survey. Interviews were conducted with adults age 18 and over representing the 50 states and the District of Columbia. Panel members were randomly drawn from AmeriSpeak. In households with more than one adult panel member, only one was selected at random for the sample. Invited panel members were given the option to complete the survey online or by telephone with an NORC telephone interviewer. The number of participants invited and percentage of interviews completed by week are as follows: 11133 invited with $19.7 \%$ interviews completed during week 1; 8570 invited with $26.1 \%$ interviews completed (week 2); and 10373 invited with $19.7 \%$ interviews completed (week 3). The analytic sample includes 10760 adults nationwide. The final analytic sample was weighted to reflect the US population of adults aged 18 years and over. The demographic weighting variables were obtained from the 2020 Current Population Survey. The count of COVID-19 deaths by county was obtained from USA Facts.

\section{Public involvement statement}

Participants were not involved in the development of this manuscript or interpretation of the results. The authors of this paper had no contact with the survey respondents and were not involved in data collection as the publicly available data were collected by NORC at the University of Chicago for the Data Foundation.

\section{Measures}

To evaluate adherence to COVID-19 preventive behaviours, we used participants' responses (yes/no) to the following question: 'Which of the following measures, if any, are you taking in response to the coronavirus?' Participants were able to select all that applied from a list of 19 options. We focused on the following commonly recommended preventive behaviours: worn a face mask; avoided some or all restaurants; avoided public or crowded places; cancelled or postponed pleasure, social 
or recreational activities; washed or sanitised hands; and kept six feet distance from those outside my household.

We defined an adult to have a physical chronic disease using participants' self-reported response (yes/no) to the following question: 'Has a doctor or other healthcare provider ever told you that you have any of the following: diabetes; high blood pressure or hypertension; heart disease, heart attack or stroke; asthma; chronic lung disease or COPD; bronchitis or emphysema; a cystic fibrosis; liver disease or end-stage liver disease; cancer; and a compromised immune system'. We defined those who selected 'yes' to any of the listed conditions as adults with a physical chronic condition.

The following covariates were included in the multivariable analyses: age categories (18-29, 30-44, 25-59, 60+), sex (male, female), education categories (high school graduate/equivalent or below, some college, baccalaureate degree or above), race/ethnicity categories (nonHispanic (NH) white, NH black, Hispanic, NH Asian, NH Other), having at least one COVID-19-related symptom, healthy with no self-reported chronic disease, census region (northeast, midwest, south, west), insurance status, household income $(<50000$, US $\$ 50000-<\mathrm{US} \$ 100000$, $\geq$ US $\$ 100000$ ) and population density (rural, suburban, urban). Population density was determined based on 2010 US Census data. ${ }^{12}$

\section{Data analysis}

Descriptive statistics were displayed in percentages among all respondents unless otherwise labelled and include a margin of error of \pm 3.0 percentage points with $95 \%$ confidence intervals (CIs) among all adults. Chisquared $\left(\chi^{2}\right)$ tests were used for bivariate comparison of preventive behaviours against the COVID-19 pandemic among adults with chronic diseases compared with others. Furthermore, we conducted multivariable Poisson regression analyses to evaluate associations of preventive behaviours with having a chronic disease after adjustment for the following variables: age, sex, race (white/ minority), area of residence (rural/suburban/urban) and annual household income. To estimate determinants of not practising COVID-19 preventive behaviours, we computed prevalence ratios with Poisson regression using robust estimation of standard errors (SEs) ${ }^{14-16}$ The COVID-19 preventive behaviours evaluated include those who responded no to all the following behaviours: worn a face mask, avoided some or all restaurants, avoided public or crowded places, cancelled or postponed pleasure, social or recreational activities, washed or sanitised hands and keep six feet distance. Potential variables for inclusion in the model were assessed using available sociodemographic variables and bivariate Poisson regression analysis. Due to the exploratory nature of this analysis using a predictive framework, an arbitrary $p$ value of $<0.10$ was used as criteria to include the variable in the multivariable Poisson regression model. Using multivariable Poisson regression models, adjusted prevalence ratios (aPR) and 95\% CIs for each independent variable were calculated. Collinearity was assessed using the variance inflation factor to ensure that a strong linear relationship among independent variables included in the model was not present. Based on the exploratory nature of this analysis, we did not include an adjustment for multiple comparisons. ${ }^{17}$ All statistical analyses were conducted using Stata IC V.15.1 (StataCorp LLC, College Station, Texas, USA). Sampling weights were applied to provide results that were nationally representative of the US adult population.

\section{RESULTS}

Table 1 summarises the demographic characteristics of the study population stratified by having a chronic disease. Participants with chronic diseases were mostly over the age of 45 years $(68.3 \%)$ and $\mathrm{NH}$ white $(65.0 \%)$. Adults with chronic diseases were $51 \%$ female and $42 \%$ were employed within the past 7 days. The majority had at least some college or baccalaureate degree or above $(60.2 \%)$ and $21 \%$ had an income over $\geq$ US $\$ 100000$. Sixty-nine percent of adults with chronic diseases lived in urban areas and $48 \%$ had an employer-sponsored insurance plan.

Figure 1 summarises preventive behaviours stratified by having a chronic disease or not across all weeks of data collection and over time from week 1 (late April) to week 3 (early June). When evaluating all weeks combined, we observed that adults without chronic diseases $(83 \%)$ were less likely to wear a mask $(87 \%)\left(\chi^{2}-\mathrm{p}<0.001\right)$. Adults with chronic diseases were not more likely to cancel or postpone pleasure, social or recreational activities $(66 \%)$ compared with adults without chronic diseases $(64 \%)$ $\left(\chi^{2}-\mathrm{p}=0.08\right)$. Next, we observed that over time adults with chronic diseases grew more likely to keep six feet distance from those outside their household: in late April there was no significant difference by chronic disease status $\left(\chi^{2}-\right.$ $\mathrm{p}=0.71$ ); however, during early May adults with chronic diseases were more likely to practice social distancing $(86 \%)$ compared with adults without chronic diseases $(80 \%)\left(\chi^{2}-p<0.001\right)$. Similarly, again, in early June, adults with chronic diseases were more likely $(86 \%)$ than adults without chronic diseases $(79 \%)\left(\chi^{2}-\mathrm{p}<0.001\right)$. We observed similar trends over time for washing or sanitising hands and avoiding some or all restaurants. Overall, adults with chronic diseases were more likely to wash or sanitise their hands $(92 \%)$ than adults without chronic diseases $(86 \%)$ $\left(\chi^{2}-\mathrm{p}<0.001\right)$. Adults with chronic diseases were also more likely $(72 \%)$ to avoid some or all restaurants than adults without chronic diseases $(69 \%)\left(\chi^{2}-\mathrm{p}=0.002\right)$ and to avoid public or crowded places ( $78 \%$ vs $74 \%) \quad\left(\chi^{2}-\mathrm{p}=0.001\right)$ (figure 1).

On multivariable analyses, after adjustment for age, race/ethnicity, sex, area of residence (rural/suburban/ urban), and household annual income, we observed significant differences across chronic disease status (figure 2). Adults with chronic diseases had a $4 \%$ higher prevalence of wearing a face mask (aPR: 1.04, 95\% CI 
Table 1 Characteristics of COVID-19 Impact Survey respondents $(n=10760)$, a nationally representative survey of the USA, stratified by cancer diagnosis (April-June 2020)

\begin{tabular}{|c|c|c|c|c|c|c|}
\hline & \multicolumn{2}{|l|}{ Total } & \multicolumn{2}{|c|}{$\begin{array}{l}\text { Adults with chronic } \\
\text { diseases }\end{array}$} & \multicolumn{2}{|c|}{$\begin{array}{l}\text { Adults without chronic } \\
\text { diseases }\end{array}$} \\
\hline & Col \% & $95 \% \mathrm{Cl}$ & Col \% & $95 \% \mathrm{Cl}$ & Col \% & $95 \% \mathrm{Cl}$ \\
\hline \multicolumn{7}{|l|}{ Age } \\
\hline $18-29$ & 20.5 & 19.3 to 21.8 & 12.8 & 11.5 to 14.3 & 29.8 & 27.7 to $31 . \mathrm{s}$ \\
\hline $30-44$ & 25.4 & 24.4 to 26.5 & 18.9 & 17.7 to 20.2 & 33.2 & 31.5 to $35 . c$ \\
\hline $45-59$ & 24.3 & 23.2 to 25.4 & 26.0 & 24.5 to 27.5 & 22.2 & 20.7 to 23.8 \\
\hline $60+$ & 29.8 & 28.6 to 30.9 & 42.3 & 40.6 to 44.0 & 14.8 & 13.5 to 16.1 \\
\hline \multicolumn{7}{|l|}{ Sex } \\
\hline Male & 48.3 & 47.0 to 49.6 & 48.2 & 46.5 to 50.0 & 48.4 & 46.4 to 50.4 \\
\hline Female & 51.7 & 50.4 to 53.0 & 51.8 & 50.0 to 53.5 & 51.6 & 49.6 to 53.6 \\
\hline \multicolumn{7}{|l|}{ Race/ethnicity } \\
\hline White, NH & 61.6 & 60.3 to 62.9 & 65 & 63.2 to 66.7 & 57.6 & 55.5 to 59.6 \\
\hline Black, NH & 11.9 & $11.0,12.7$ & 13.3 & 12.1 to 14.5 & 10.2 & 9.1 to 11.4 \\
\hline Hispanic & 16.5 & 15.5 to 17.7 & 12.9 & 11.7 to 14.2 & 20.9 & 19.1 to $22 . \varepsilon$ \\
\hline Asian, NH & 5.1 & 4.4 to 5.8 & 3.4 & 2.7 to 4.3 & 7.1 & 5.9 to 8.4 \\
\hline Other, NH & 3.5 & 3.1 to 3.9 & 3.9 & 3.4 to 4.6 & 2.9 & 2.5 to 3.5 \\
\hline Employed in the past 7 days & 49.7 & 48.4 to 51.1 & 42 & 40.3 to 43.7 & 59.1 & 57.1 to 61.1 \\
\hline \multicolumn{7}{|l|}{ Education } \\
\hline No HS diploma & 9.8 & 8.8 to 10.8 & 10.3 & 9.1 to 11.8 & 9.1 & 7.7 to 10.7 \\
\hline HS graduate & 28.2 & 27.0 to 29.6 & 29.4 & 27.7 to 31.1 & 26.9 & 24.9 to 29.0 \\
\hline Some college & 27.7 & 26.7 to 28.7 & 29.4 & 28.1 to 30.8 & 25.7 & 24.2 to 27.2 \\
\hline Baccalaureate or above & 34.3 & 33.1 to 35.5 & 30.8 & 29.3 to 32.4 & 38.4 & 36.5 to 40.3 \\
\hline \multicolumn{7}{|l|}{ Household income } \\
\hline$<$ US $\$ 50000$ & 45.8 & 44.5 to 47.1 & 49.7 & 48.0 to 51.4 & 41.1 & 39.1 to 43.2 \\
\hline$\$$ US50,000-<US $\$ 100000$ & 32.1 & 30.9 to 33.3 & 29.1 & 27.6 to 30.7 & 35.6 & 33.7 to 37.5 \\
\hline$\geq$ US $\$ 100000$ & 22.1 & 21.1 to 23.2 & 21.2 & 19.8 to 22.6 & 23.3 & 21.6 to 25.0 \\
\hline \multicolumn{7}{|l|}{ Population density } \\
\hline Rural & 9.1 & 8.4 to 9.8 & 10.5 & 9.5 to 11.6 & 7.4 & 6.5 to 8.4 \\
\hline Suburban & 18.8 & 17.8 to 19.7 & 20.5 & 19.2 to 21.9 & 16.7 & 15.4 to 18.1 \\
\hline Urban & 72.2 & 71.0 to 73.3 & 69 & 67.4 to 70.5 & 75.9 & 74.3 to 77.5 \\
\hline \multicolumn{7}{|l|}{ Census region } \\
\hline Northeast & 17.4 & 16.4 to 18.5 & 17.9 & 16.5 to 19.3 & 16.9 & 15.3 to 18.6 \\
\hline Midwest & 20.7 & 19.8 to 21.7 & 21.7 & 20.4 to 23.1 & 19.5 & 18.2 to $21 . c$ \\
\hline South & 38.0 & 36.7 to 39.3 & 38.6 & 36.9 to 40.3 & 37.3 & 35.3 to 39.3 \\
\hline West & 23.8 & 22.8 to 24.9 & 21.8 & 20.4 to 23.2 & 26.3 & 24.6 to 28.1 \\
\hline \multicolumn{7}{|l|}{ Insurance type or health coverage plans } \\
\hline Purchased plan & 17.4 & 16.4 to 18.5 & 18.9 & 17.5 to 20.3 & 15.7 & 14.2 to 17.4 \\
\hline Employer-sponsored & 51.7 & 50.3 to 53.0 & 48 & 46.2 to 49.7 & 56.1 & 54.1 to 58.1 \\
\hline TRICARE & 4.9 & 4.4 to 5.4 & 5.3 & 4.6 to 6.1 & 4.4 & 3.8 to 5.2 \\
\hline Medicaid & 23.5 & 22.4 to 24.7 & 28.1 & 26.5 to 29.8 & 18 & 16.5 to 19.6 \\
\hline Medicare & 25.3 & 24.2 to 26.4 & 36.9 & 35.3 to 38.6 & 11.3 & 10.1 to 12.6 \\
\hline Dually eligible (medicare and medicaid) & 9.7 & 9.0 to 10.4 & 14.6 & 13.4 to 15.8 & 3.8 & 3.2 to 4.6 \\
\hline Veterans Affairs & 4.5 & 4.0 to 5.0 & 5.7 & 5.0 to 6.6 & 3 & 2.5 to 3.6 \\
\hline Indian health service & 1.2 & 0.9 to 1.6 & 1.6 & 1.1 to 2.2 & 0.7 & 0.4 to 1.3 \\
\hline No insurance & 8.8 & 8.1 to 9.6 & 6.3 & 5.5 to 7.2 & 11.9 & 10.5 to 13.3 \\
\hline
\end{tabular}

HS, high school; $\mathrm{NH}$, non-Hispanic. 
ㅁ Without Chronic Diseases

- With Chronic Disease
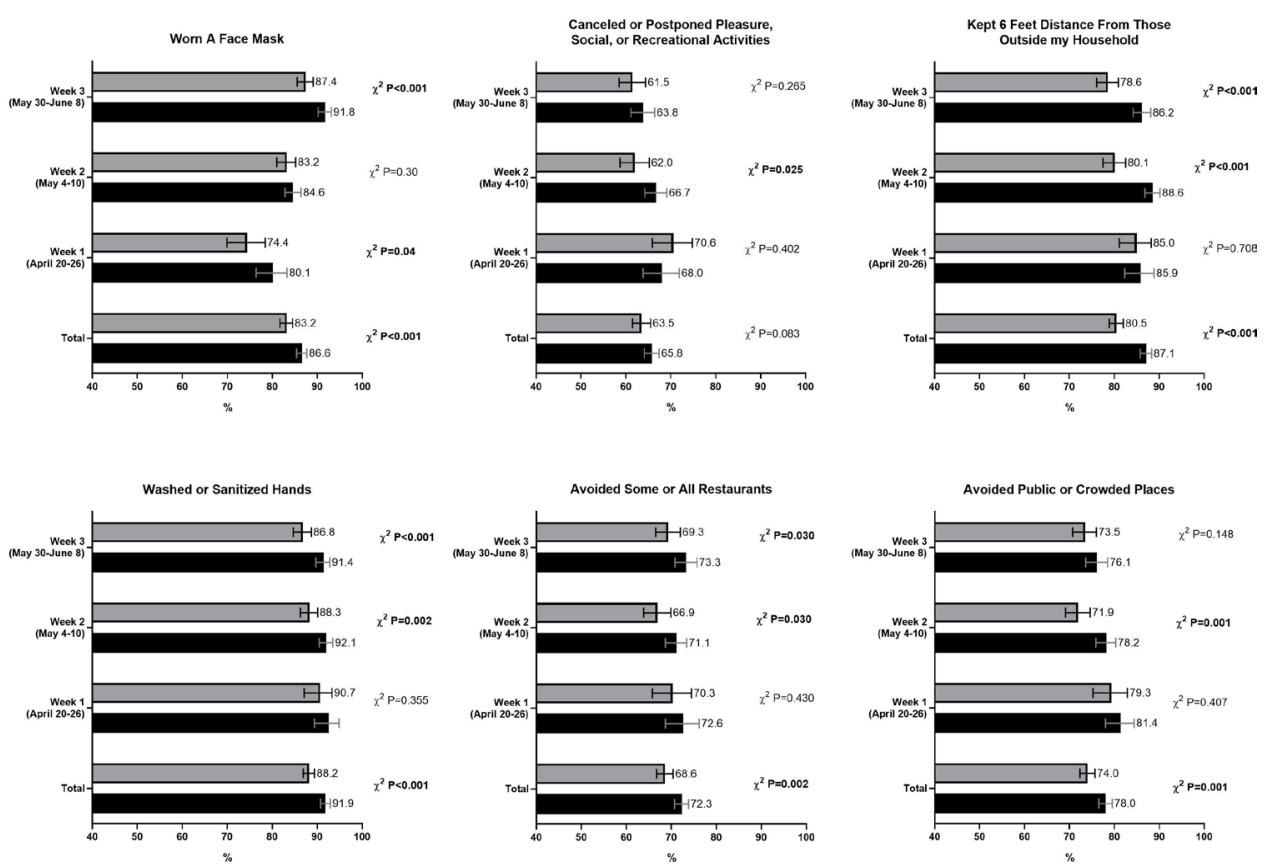

Figure 1 Adherence to COVID-19 preventive behaviours among those without chronic diseases compared with those with chronic diseases in the USA.

1.01 to 1.06$)$, avoiding some or all restaurants (aPR: 1.04, 95\% CI 1.01 to 1.08 ), avoiding public or crowded places (aPR: $1.04,95 \%$ CI 1.01 to 1.07 ) and keeping six feet distance (aPR: 1.04, 95\% CI 1.02 to 1.07 ). Additionally, adults with chronic diseases had a $2 \%$ higher prevalence of washing or sanitising hands (aPR: $1.02,95 \%$ CI 1.01 to $1.04)$.

Table 2 summarises results of multivariable analyses to identify determinants of not adhering to recommended COVID-19 preventive behaviours. Overall, $2.4 \%$ of
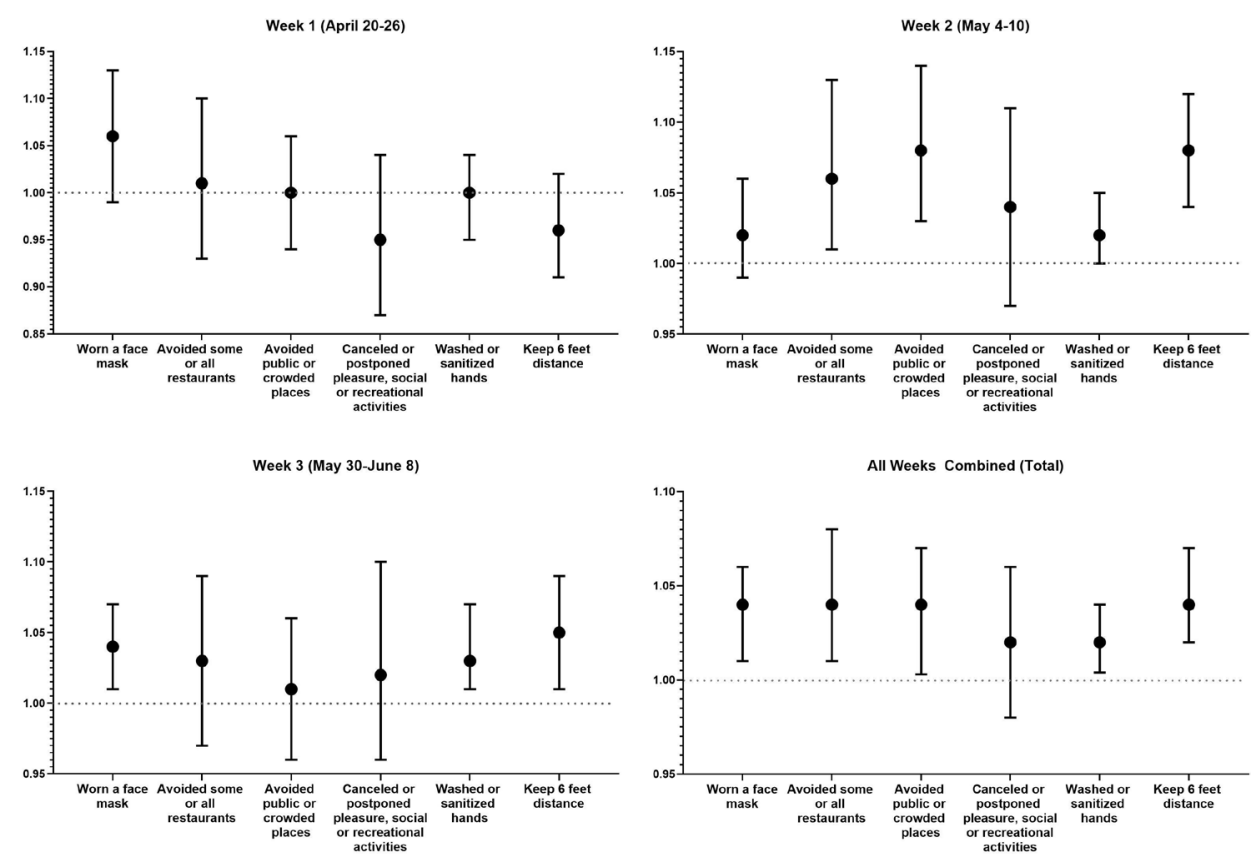

X-Axis: Preventive Behaviors | Y-Axis:Adjusted Prevalence Ratio and 95\% Confidence Intervals

Models adjusted for: Age, race/ethnicity, sex, area of residence (rural, suburban, urban), household annual income

Figure 2 Associations of adherence to COVID-19 preventive behaviours among US adults with chronic diseases 
Table 2 Determinants of not adhering to recommended COVID-19 preventive behaviours* using COVID-19 Impact Survey, a nationally representative survey of the USA ( $n=10760)$ (April-June 2020)

\begin{tabular}{|c|c|c|c|c|}
\hline & Unadjusted & & Adjusted & \\
\hline & & $95 \% \mathrm{Cl}$ & PR & $95 \% \mathrm{Cl}$ \\
\hline \multicolumn{5}{|l|}{ Age } \\
\hline $18-29$ & 2.55 & $\begin{array}{l}1.33 \text { to } \\
4.91\end{array}$ & 1.41 & $\begin{array}{l}0.64 \text { to } \\
3.13\end{array}$ \\
\hline $30-44$ & 2.08 & $\begin{array}{l}1.64 \text { to } \\
3.73\end{array}$ & 1.41 & $\begin{array}{l}0.77 \text { to } \\
2.57\end{array}$ \\
\hline $45-59$ & 2.27 & $\begin{array}{l}1.24 \text { to } \\
4.18\end{array}$ & 1.75 & $\begin{array}{l}0.95 \text { to } \\
3.25\end{array}$ \\
\hline $60+$ & Ref. & & Ref. & \\
\hline
\end{tabular}

Sex

\begin{tabular}{|c|c|c|c|c|}
\hline Male & Ref. & & Ref. & \\
\hline Female & 0.47 & $\begin{array}{l}0.32 \text { to } \\
0.68\end{array}$ & 0.47 & $\begin{array}{l}0.32 \text { to } \\
0.69\end{array}$ \\
\hline \multicolumn{5}{|l|}{ Education } \\
\hline $\begin{array}{l}\text { HS graduate or } \\
\text { below }\end{array}$ & 2.45 & $\begin{array}{l}1.43 \text { to } \\
4.22\end{array}$ & 1.86 & $\begin{array}{l}1.06 \text { to } \\
3.27\end{array}$ \\
\hline Some College & 1.82 & $\begin{array}{l}1.08 \text { to } \\
3.07\end{array}$ & 1.49 & $\begin{array}{l}0.87 \text { to } \\
2.54\end{array}$ \\
\hline $\begin{array}{l}\text { Baccalaureate or } \\
\text { above }\end{array}$ & Ref. & & Ref. & \\
\hline \multicolumn{5}{|l|}{ Race/ethnicity } \\
\hline White, $\mathrm{NH}$ & Ref. & & Ref. & \\
\hline Black, NH & 1.05 & $\begin{array}{l}0.62 \text { to } \\
1.77\end{array}$ & 1.01 & $\begin{array}{l}0.56 \text { to } \\
1.83\end{array}$ \\
\hline Hispanic & 1.20 & $\begin{array}{l}0.70 \text { to } \\
2.07\end{array}$ & 0.97 & $\begin{array}{l}0.48 \text { to } \\
1.96\end{array}$ \\
\hline Asian, NH & 0.37 & $\begin{array}{l}0.15 \text { to } \\
0.94\end{array}$ & 0.44 & $\begin{array}{l}0.16 \text { to } \\
1.22\end{array}$ \\
\hline Other, NH & 0.74 & $\begin{array}{l}0.40 \text { to } \\
1.39\end{array}$ & 0.76 & $\begin{array}{l}0.41 \text { to } \\
.141\end{array}$ \\
\hline $\begin{array}{l}\text { At least one } \\
\text { COVID-19-related } \\
\text { symptom† }\end{array}$ & 0.77 & $\begin{array}{l}0.54 \text { to } \\
1.10\end{array}$ & - & \\
\hline $\begin{array}{l}\text { No physical } \\
\text { chronic diseases } \ddagger\end{array}$ & 2.03 & $\begin{array}{l}1.39 \text { to } \\
2.97\end{array}$ & 1.78 & $\begin{array}{l}1.24 \text { to } \\
2.55\end{array}$ \\
\hline \multicolumn{5}{|l|}{ Region } \\
\hline Northeast & 0.47 & $\begin{array}{l}0.23 \text { to } \\
0.96\end{array}$ & 0.55 & $\begin{array}{l}0.26 \text { to } \\
1.16\end{array}$ \\
\hline Midwest & 1.01 & $\begin{array}{l}0.66 \text { to } \\
1.55\end{array}$ & 1.02 & $\begin{array}{l}0.64 \text { to } \\
1.62\end{array}$ \\
\hline South & Ref. & & Ref. & \\
\hline West & 0.85 & $\begin{array}{l}0.55 \text { to } \\
1.33\end{array}$ & 0.89 & $\begin{array}{l}0.54 \text { to } \\
1.47\end{array}$ \\
\hline Employed & 1.62 & $\begin{array}{l}1.11 \text { to } \\
2.35\end{array}$ & 1.48 & $\begin{array}{l}1.02 \text { to } \\
2.17\end{array}$ \\
\hline Uninsured & 2.60 & $\begin{array}{l}1.76 \text { to } \\
3.83\end{array}$ & 1.79 & $\begin{array}{l}1.16 \text { to } \\
2.75\end{array}$ \\
\hline
\end{tabular}

Household income
Table 2 Continued

\begin{tabular}{|c|c|c|c|c|}
\hline & Unadjusted & & Adjusted & \\
\hline & PR & $95 \% \mathrm{Cl}$ & PR & $95 \% \mathrm{Cl}$ \\
\hline$<$ US $\$ 50000$ & 2.66 & $\begin{array}{l}1.56 \text { to } \\
4.54\end{array}$ & 2.05 & $\begin{array}{l}1.14 \text { to } \\
2.85\end{array}$ \\
\hline $\begin{array}{l}\text { US } \$ 50,000- \\
<\text { US } \$ 100000\end{array}$ & 2.24 & $\begin{array}{l}1.26 \text { to } \\
4.01\end{array}$ & 1.33 & $\begin{array}{l}0.85 \text { to } \\
2.08\end{array}$ \\
\hline$\geq$ US\$100000 & Ref. & & Ref. & \\
\hline \multicolumn{5}{|c|}{ Population density } \\
\hline Rural & 1.81 & $\begin{array}{l}1.14 \text { to } \\
2.87\end{array}$ & 1.70 & $\begin{array}{l}1.01 \text { to } \\
2.85\end{array}$ \\
\hline Suburban & 1.53 & $\begin{array}{l}1.03 \text { to } \\
2.29\end{array}$ & 1.33 & $\begin{array}{l}0.85 \text { to } \\
2.08\end{array}$ \\
\hline Urban & Ref. & & Ref. & \\
\hline
\end{tabular}

*The COVID-19 preventive behaviours included in this definition are those who responded no to all the following behaviours: worn a face mask, avoided some or all restaurants, avoided public or crowded places, cancelled or postponed pleasure, social or recreational activities, washed or sanitised hands and keep six feet distance.

†Symptoms include: fever, chills, runny or stuffy nose, chest congestion, skin rash, cough, sore throat, sneezing, muscle or body aches, headaches, fatigue or tiredness, shortness of breath, abdominal discomfort, nausea or vomiting, diarrhoea, changed or loss sense of taste or smell, loss of appetite. $\ddagger$ Physical chronic diseases include diabetes, high blood pressure, heart disease/heart attack/stroke, asthma, chronic obstructive pulmonary disease or COPD, bronchitis or emphysema, cystic fibrosis, liver disease, a compromised immune system and cancer.

$\mathrm{HS}$, high school; $\mathrm{NH}$, non-Hispanic; PR, prevalence ratio.

adults responded no to all the following behaviours: worn a face mask, avoided some or all restaurants, avoided public or crowded places, cancelled or postponed pleasure, social or recreational activities, washed or sanitised hands and keep six feet distance from those living outside their home. Non-adherence to recommended preventive behaviours was more likely among adults with a high school degree or below compared with those with a baccalaureate degree or above (aPR: $1.86,95 \%$ CI 1.06 to 3.27). Additionally, non-adherence to recommended behaviours was more likely among adults without any chronic diseases (aPR: 1.78, 95\% CI 1.24 to 2.55 ) as well as the employed (aPR: $1.48,95 \%$ CI 1.02 to 2.17 ) and the uninsured (aPR: $1.79,95 \% \mathrm{CI}$ 1.16 to 2.75$)$. Adults with a household income less than US $\$ 50000$ were more likely not to adhere to preventive behaviours compared with those with an income over US $\$ 100000$ (aPR: $2.05,95 \%$ CI 1.14 to 2.85 ). Compared with adults living in urban areas, adults in rural areas had a $70 \%$ higher prevalence of non-adherence to recommended preventive behaviours. Non-adherence to recommended preventive behaviours was less likely among female adults compared with male adults (aPR: $0.47,95 \%$ CI 0.32 to 0.69 ). 


\section{DISCUSSION}

In this analysis, we found that compared with adults without chronic diseases, adults with chronic diseases were more likely to adhere to recommended preventive behaviours to reduce the spread of COVID-19 in the USA. These findings are consistent with our prior study examining associations of COVID-19 preventive behaviours with chronic disease status at the onset of the COVID-19 pandemic. ${ }^{7}$ Here, we extend our previous analysis to identify determinants of non-adherence to COVID-19 preventive behaviours among US adults. We observed that non-adherence to COVID-19 preventive behaviours was more likely among adults who are middle aged, with less education, lower income, uninsured, employed, residing in rural and suburban areas and those without any selfreported physical chronic disease. Previous studies have documented disparities in adherence to COVID-19 preventive behaviours by education, occupation, urbanicity and occupation. ${ }^{18}$ As the effectiveness of preventive behaviours, including mask use and social distancing, in mitigating the spread of COVID-19, has been demonstrated, these findings have implications for preventive public health messaging to identifiy demographic targets for improved education and improved allocation of resources. ${ }^{19-21}$

Our findings indicate that US adults with lower socioeconomic status, including lower income, educational background, and the uninsured, are less likely to adhere to COVID-19-recommended preventive behaviours. These findings may indicate that those with lower socioeconomic status experience significant barriers to practicing preventive behaviours due to inequitable access to healthcare, resources and the ability to take off from work as we also observed those who were employed were more likely to not adhere to COVID-19 preventive behaviours. Prior studies have documented the higher risk of COVID-19 among essential workers due to difficulties in social distancing, inadequate access to personal protective equipment and lack of COVID-19-specific disinfection guidelines. ${ }^{22}{ }^{23}$ Additionally, associations between lower levels of education and less understanding of public health messaging around COVID-19 preventive behaviours and greater endorsement of COVID-19 misinformation (eg, underestimating importance of social distancing, misinformed beliefs around COVID-19 vaccination) have been documented in the USA and beyond. ${ }^{24}{ }^{25}$ Conversely, our study findings may also reflect changes in attitudes around COVID-19 preventive behaviours. ${ }^{26}$ Prior studies examining the associations between COVID-19 information sources and attitudes towards COVID-19 messaging have elucidated differences in trust of COVID-19 information and self-reported adherence to COVID-19 preventive behaviours among men, individuals who are unemployed or retired, and adults who politically identify as Republican. ${ }^{27-30}$ While we were unable to adjust for political affiliation within our analyses due to the lack of data availability within the COVID-19 Impact Survey, research shows that $\mathrm{NH}$ whites, men and individuals residing in rural areas more frequently identify their political affiliation as Republican. ${ }^{31}{ }^{32}$ Our observed geographic disparities in COVID-19 preventive behaviours may also be a reflection of variability in state or local policies regarding COVID-19 preventive behaviours across the individuals residing in US states and counties that have implemented mandatory COVID-19 preventive behaviours, including stay-at-home orders, social distancing and mandatory mask use in public, are more likely to exhibit positive individual-level COVID-19 preventive behaviours. ${ }^{33-35}$ Inequities in ability or willingness to practice COVID-19 preventive behaviours may lead to inequitable risk and morbidity of COVID-19 among these at-risk groups. Future research should focus on the impact of state-level COVID-19 prevention policies to evaluate area-level differences in individual preventive behaviours and to disentangle whether certain demographics of US adults are either unwilling or unable to adhere to recommended guidelines.

Importantly, we found that adults without any chronic diseases were more likely to not adhere to practice preventive behaviours, which indicates the potential for improvement among public health professionals in communicating risk to impact risk perception. Prior studies have shown that higher perceived risk of infection and COVID-19 disease had a positive impact on implementation of protective behaviours such as handwashing and social distancing. ${ }^{36}$ Early in the pandemic, one study found that on a scale from $0 \%$ to $100 \%$, the average perceived risk of infection incidence was $10 \%$ and $5 \%$ for mortality, and perceived risk had a positive impact on practising preventive behaviours: an increase of one quartile in perceived infection risk was associated with $45 \%$ and $24 \%$ higher odds of reporting handwashing and social distancing, respectively. ${ }^{37}$ Similarly, another study found that the perceived risk of infection increased from March to April; however, US adults severely underestimated their absolute and relative fatality risk compared with epidemiological figures available at the time of the study. They also found that the participant's risk perception highly influenced their actual or intended adherence to preventive behaviours that can reduce COVID-19 spread. ${ }^{36}$ Our findings complement these prior studies and underscore the need for improved risk communication specifically among the demographic groups we identified. The public health and medical community working to address the COVID-19 pandemic should also be aware that risk communication alone may not meet the needs of certain demographic groups, and equitable access to resources or opportunities to practice recommended preventive behaviours should be coupled into preventive programming.

Our study findings are subject to several limitations. First, behaviours and practice of recommendations were self-reported; therefore, responses might be subjected to recall, response and social desirability biases. Second, while we were able to adjust for many social and demographic characteristics, we were limited by the availability of the data and may have failed to account for unmeasured 
variables associated with practice of preventive behaviours and chronic conditions. We were unable to probe further into why adults may not be adhering to recommended COVID-19 prevention behaviours as those data were not available. Future qualitative studies should be prioritised to ask more detailed questions regarding attitudes and perceptions of COVID-19 recommended preventive behaviours in the USA. The percentage of rural adults included in this sample was lower than expected, potentially due to differences in response rates by area of residence, and as such, future efforts to survey rural adults on their preventive behaviours should be specifically prioritised. Strengths include the incorporation of multiple cross-sectional waves of data to understand COVID-19 preventive behaviours over time, use of a nationally representative sample of US adults and examination of a broad range of COVID-19 preventive behaviours.

As the pandemic progresses and subsequent outbreaks occur, understanding public behaviours and determinants of preventive behaviours are critical. The practice of recommendations to wear cloth face coverings, physical distancing and quarantine guidelines is of utmost public health importance. Overall, strong public adherence to these behaviours suggests an opportunity to normalise and continue to promote safe practices as states reopen, while disparities in practice of behaviours among specific demographic groups offer opportunities for targeted outreach and education.

\section{Twitter Jessica Y. Islam @jyislam and Denise C.Vidot @DrDeniseVidot}

Acknowledgements We gratefully acknowledge NORC at the University of Chicago for the Data Foundation for their efforts in data collection and making the COVID Impact Survey data publicly available.

Contributors JYI conceptualised the manuscript, guided data analysis, interpreted critically, wrote the manuscript; MC-R and DV contributed to data interpretation and manuscript writing. All authors have read and approved the submission.

Funding JYI is supported by UNC's Cancer Care Quality Training 2T32CA11633911. MCR is supported by the TRANSPORT-The Translational Program of Health Disparities Research Training 5S21MD012474-02.

\section{Competing interests None declared.}

Patient and public involvement Patients and/or the public were not involved in the design, or conduct, or reporting, or dissemination plans of this research.

\section{Patient consent for publication Not required.}

Provenance and peer review Not commissioned; externally peer reviewed.

Data availability statement Data are available in a public, open access repository. Data are publically available at the following website: https://www.covid-impact. org/results.

Open access This is an open access article distributed in accordance with the Creative Commons Attribution Non Commercial (CC BY-NC 4.0) license, which permits others to distribute, remix, adapt, build upon this work non-commercially, and license their derivative works on different terms, provided the original work is properly cited, appropriate credit is given, any changes made indicated, and the use is non-commercial. See: http://creativecommons.org/licenses/by-nc/4.0/.

\section{ORCID iD}

Jessica Y. Islam http://orcid.org/0000-0002-3690-3848
REFERENCES

1 CDC. Cases and deaths in the U.S. Available: https://www.cdc. gov/coronavirus/2019-ncov/cases-updates/us-cases-deaths.html [Accessed 15 Aug 2020].

2 CDC. Certain medical conditions and risk for severe COVID-19 illness. Available: https://www.cdc.gov/coronavirus/2019-ncov/needextra-precautions/people-with-medical-conditions.html?CDC_AA refVal=https \%3A\%2F\%2Fwww.cdc.gov\%2Fcoronavirus\%2F $201 \overline{9}$ ncov\%2Fneed-extra-precautions\%2Fgroups-at-higher-risk.html [Accessed 15 Aug 2020].

3 CDC. How to protect yourself \& others. Available: https://www.cdc gov/coronavirus/2019-ncov/prevent-getting-sick/prevention.html [Accessed 13 Aug 2020].

4 Prevent Epidemics. 3 W's to reduce the risk of COVID-19. Available: https://preventepidemics.org/covid19/science/insights/3-ws-toreduce-the-risk-of-covid-19/ [Accessed 15 Aug 2020].

5 WSJ. As coronavirus surges in U.S., some countries have just about halted it. Available: https://www.wsj.com/articles/ascoronavirus-surges-in-u-s-some-countries-have-just-about-halted-it11594037814 [Accessed 15 Aug 2020].

6 NPR. How some countries brought new coronavirus cases down to nearly zero : goats and soda. Available: https://www.npr.org/ sections/goatsandsoda/2020/05/23/861577367/messaging-fromleaders-who-have-tamed-their-countrys-coronavirus-outbreaks [Accessed 15 Aug 2020].

7 Camacho-Rivera M, Islam JY, Vidot DC. Associations between chronic health conditions and COVID-19 preventive behaviors among a nationally representative sample of U.S. adults: an analysis of the COVID impact survey. Health Equity 2020;4:336-44.

8 The New York Times. A detailed map of who is wearing masks in the U.S. Available: https://www.nytimes.com/interactive/2020/07/17/ upshot/coronavirus-face-mask-map.html [Accessed 17 Aug 2020].

9 CDC COVID data tracker. Available: https://www.cdc.gov/coviddata-tracker/ [Accessed 17 Aug 2020].

10 Here are the states where COVID-19 is increasing. Available: https:// www.healthline.com/health-news/here-are-the-states-where-covid19-is-increasing [Accessed 17 Aug 2020].

11 COVID impact survey. Available: https://www.covid-impact.org/ [Accessed 20 May 2020].

12 Wozniak A, Willey J, Benz J. The COVID impact survey: methodological approach. National Opinion Research Center, 2020. http://static1.squarespace.com/static/5e8769b34812765cff8111f7/ t/5ee116321eed0b743254564c/1591809593661/COVID Impact Methods Statement_wk3_web.pdf

13 Islam JY, Camacho-Rivera M, Vidot DC. Examining COVID-19 preventive behaviors among cancer survivors in the United States: an analysis of the COVID-19 impact survey. Cancer Epidemiol Biomarkers Prev 2020;29:2583-90.

14 Barros AJD, Hirakata VN. Alternatives for logistic regression in crosssectional studies: an empirical comparison of models that directly estimate the prevalence ratio. BMC Med Res Methodol 2003;3:21.

15 Behrens T, Taeger D, Wellmann J, et al. Different methods to calculate effect estimates in cross-sectional studies. A comparison between prevalence odds ratio and prevalence ratio. Methods Inf Med 2004;43:505-9.

16 Coutinho LMS, Scazufca M, Menezes PR. Methods for estimating prevalence ratios in cross-sectional studies. Rev Saude Publica 2008;42:992-8.

17 Rothman KJ. No adjustments are needed for multiple comparisons. Epidemiology 1990;1:43-6.

18 Yue S, Zhang J, Cao M. Knowledge, attitudes and practices of COVID-19 among urban and rural residents in China: a crosssectional study. J Community Health 2020 doi:10.1007/s10900-02000877-X

19 Thu TPB, Ngoc PNH, Hai NM, et al. Effect of the social distancing measures on the spread of COVID-19 in 10 highly infected countries. Sci Total Environ 2020;742:140430.

20 Siedner MJ, Harling G, Reynolds Z, et al. Social distancing to slow the US COVID-19 epidemic: longitudinal pretest-posttest comparison group study. PLoS Med 2020;17:e1003244.

21 Koh WC, Alikhan MF, Koh D, et al. Containing COVID-19: implementation of early and moderately stringent social distancing measures can prevent the need for large-scale Lockdowns. Ann Glob Health 2020;86:88.

22 Dyal JW, Grant MP, Broadwater K, et al. COVID-19 among workers in meat and poultry processing facilities - 19 states, April 2020. MMWR Morb Mortal Wkly Rep 2020;69:1. doi:10.15585/mmwr. $\mathrm{mm} 6918 \mathrm{e} 3$

23 McClure ES, Vasudevan P, Bailey Z. Racial capitalism within public health: how occupational settings drive COVID-19 disparities. Am J Epidemiol. 
24 Bailey SC, Serper M, Opsasnick L, et al. Changes in COVID-19 knowledge, beliefs, behaviors, and preparedness among high-risk adults from the onset to the acceleration phase of the US outbreak. $J$ Gen Intern Med 2020;35:3285-92.

25 O'Conor R, Opsasnick L, Benavente JY, et al. Knowledge and behaviors of adults with underlying health conditions during the onset of the COVID-19 U.S. outbreak: the Chicago COVID-19 comorbidities survey. J Community Health 2020;45:1149-57.

26 Czeisler Mark É, Tynan MA, Howard ME, et al. Public attitudes, behaviors, and beliefs related to COVID-19, stay-at-home orders, nonessential business closures, and public health guidance - United States, New York City, and Los Angeles, May 5-12, 2020. MMWR Morb Mortal Wkly Rep 2020;69:751-8.

27 Ali SH, Foreman J, Tozan Y, et al. Trends and predictors of COVID-19 information sources and their relationship with knowledge and beliefs related to the pandemic: nationwide cross-sectional study. JMIR Public Health Surveill 2020;6:e21071.

28 Dhanani LY, Franz B. The role of news consumption and trust in public health leadership in shaping COVID-19 knowledge and prejudice. Front Psychol 2020;11:560828.

29 Nagler RH, Vogel RI, Gollust SE, et al. Public perceptions of conflicting information surrounding COVID-19: results from a nationally representative survey of U.S. adults. PLoS One 2020;15:e0240776.

30 Callow MA, Callow DD, Smith C. Older adults' intention to socially isolate once COVID-19 stay-at-home orders are replaced with "safer-at-home" public health advisories: a survey of respondents in Maryland. J App/ Gerontol 2020;39:1175-83.

31 Lesthaeghe R, Neidert L. US presidential elections and the spatial pattern of the American second demographic transition. Popul Dev Rev 2009;35:391-400.

32 Stoetzer MW, Gerlich S, Koesters J. Trump's first triumph: The US republican primaries 2016-An analysis of socio-demographic, timerelated and regional influences, 2017.

33 Liu Y, Mattke S. Association between state stay-at-home orders and risk reduction behaviors and mental distress amid the COVID-19 pandemic. Prev Med 2020;141:106299.

34 Van Dyke ME, Rogers TM, Pevzner E, et al. Trends in county-level COVID-19 incidence in counties with and without a mask mandate - Kansas, June 1-August 23, 2020. MMWR Morb Mortal Wkly Rep 2020;69:1777-81.

35 Gallaway MS, Rigler J, Robinson S, et al. Trends in COVID-19 incidence after implementation of mitigation measures - Arizona, January 22-August 7, 2020. MMWR Morb Mortal Wkly Rep 2020;69:1460-3.

36 Niepel C, Kranz D, Borgonovi F, et al. The coronavirus (COVID-19) fatality risk perception of US adult residents in March and April 2020. Br J Health Psychol 2020;25:883-8.

37 Bruine de Bruin W, Bennett D. Relationships between initial COVID-19 risk perceptions and protective health behaviors: a national survey. Am J Prev Med 2020;59:157-67. 